Revista lus et Praxis, Año 16, No 1, 2010, pp. 303 - 332

ISSN 0717 - 2877

Universidad de Talca - Facultad de Ciencias Jurídicas y Sociales

"El principio de capacidad económica como principio jurídico material de la tributación: su elaboración doctrinal y jurisprudencial en España"

Patricio Masbernat Muñoz

\title{
EL PRINCIPIO DE CAPACIDAD ECONÓMICA COMO PRINCIPIO JURÍDICO MATERIAL DE LA TRIBUTACIÓN: SU ELABORACIÓN DOCTRINAL Y JURISPRUDENCIAL EN ESPAÑA ${ }^{* * * * *}$ \\ The Principle of Ability to Pay as Juridical Tax Principle: Doctrinal and Jurisprudential Construction in Spain
}

Patricio Masbernat Muñoz ${ }^{* * *}$

\begin{abstract}
RESUMEN
El presente artículo comunica acerca de la configuración normativa y la elaboración doctrinaria y jurisprudencial del principio de capacidad económica en España. El autor persigue dar a conocer en Chile una institución jurídica que es reconocida en los ordenamientos europeos y que constituye la base esencial sobre la cual se construyen sus sistemas tributarios, a objeto de que sea incorporada en Chile a través de una elaboración teórica propia a partir de los materiales normativos nacionales. Por lo anterior, el autor entrega fundamentos para justificar dicha incorporación y suministra elementos para adaptar este principio en el ordenamiento jurídico chileno. Las cuestiones contenidas en esta comunicación son amplias y complejas, propiamente se insertan en la teoría de los principios materiales de la tributación, y es la razón por la cual el autor construye su discurso a través de varios pasos independientes en una serie de artículos.
\end{abstract}

\section{ABSTRACT}

The present paper communicates about the normative configuration and the doctrinal and jurisprudential elaboration of the principle of capacity to pay in Spain. The author seeks to make known in Chile a legal institution that is recognized in the European legal systems and which constitutes the essential basis of their tax systems, in order to be incorporated in Chile through an own theoretical elaboration on the basis of the national normative materials. By the previous thing, the author gives reasons to justify this incorporation and provides elements to adapt this principle in the Chilean legal order. The issues contained in this communication are vast and complex, they are

\footnotetext{
* Trabajo recibido el 15 de diciembre de 2009 y aprobado el 21 de abril de 2010.

** El autor agradece la revisión formal efectuada y las importantes sugerencias entregadas por la profesora Nancy Masbernat a la última versión de este artículo. Con todo, los errores que pudieren persistir son de exclusiva responsabilidad del autor.

*** Licenciado en Derecho por la Pontificia Universidad Católica de Chile; Magíster en Derecho por la Universidad de Chile; Doctor en Derecho por la Universidad Complutense de Madrid; Profesor de Derecho Tributario, Derecho Económico y Teoría Económica en la Universidad de Talca. Correo electrónico: pmasbernatt@utalca.cl.
} 
inserted in the theory of the principles of tax justice, and is the reason for which the author builds his speech through several independent steps in a series of papers.

Palabras Clave

Capacidad Económica, Capacidad de Pago, Capacidad Contributiva, Principios de Justicia Tributaria, Igualdad Tributaria

KEY WORDS

Principles of Tax Justice, Ability to Pay Principle, Tax Equality, Constitutional Jurisprudence

\section{INTRODUCCIÓN ${ }^{* * * *}$}

Este trabajo se encuentre inserto en una serie de publicaciones que persigue dos objetivos centrales. Por un lado, el de poner en evidencia el déficit de la construcción doctrinal de los principios materiales de la tributación en Chile, en el sentido que en nuestro medio no existe consenso acerca de cuáles son los principios de la tributación; cuáles sus contenidos; y cómo impactan en el sistema tributario. Por otro lado, el de plantear la necesidad de incorporar el principio de capacidad económica ${ }^{1}$ como principio propiamente jurídico, renunciando al enfoque hacendístico o economicista que ha sido sustentado hasta ahora, aun inadvertidamente, por la doctrina nacional.

En efecto, en nuestro medio sólo un autor ha tratado este principio en función de su carácter autónomo y jurídico, aunque sólo en referencia al Derecho Español y sin ningún análisis crítico en orden a determinar de qué modo los planteamientos de Derecho extranjero son posibles de integrarse en nuestro ordenamiento conforme a nuestros propios materiales normativos ${ }^{2}$. Otro autor enfoca dicho principio como parte del principio de igualdad, con un confuso contenido hacendístico y no sólo jurídico, y un escaso análisis crítico acerca de lo que se ha debatido últimamente en España; al igual que el caso anterior, el análisis se sustenta en el Derecho Español o extranjero (especialmente de otros países latinoamericanos) sin construir una teoría que haga posible su in-

\footnotetext{
${ }^{* * * *}$ ABREVIATURAS: CE: Constitución Española; FJ: Fundamento Jurídico de una sentencia (considerando); S: sentencia; SS: sentencias; TCE: Tribunal Constitucional Español.

${ }^{1}$ Usaré principalmente el término "capacidad económica", y de modo intercambiable, el de capacidad de pago y el de capacidad contributiva, si bien reconozco las diferencias que la doctrina ha reconocido entre ellos. Ver, al respecto, Gandra Da Silva Martins, Ives, "Capacidad económica y capacidad contributiva", Revista de Derecho Financiero y de Hacienda Pública № 212 Vol. 41, 1991, pp. 235-260. Eseverri, explica del siguiente modo la distinción entre ambos institutos. La capacidad contributiva, a su juicio, se proyecta sobre todos los ciudadanos y expresa la necesidad de que todos ellos concurran a sufragar gastos del Estado. A su turno, la capacidad económica tiene por función modular dicha llamada a la concurrencia a sufragar los gastos públicos con arreglo al nivel de riqueza de cada individuo y se trataría de un mandato al legislador encargado de configurar el sistema tributario. Eseverri Martínez, Ernesto, Derecho Tributario: Parte General, Tirant Lo Blanch, Valencia, 2006, p. 29.

2 Radovic Schoepen, Ángela, Obligación tributaria, Editorial Jurídica ConoSur, Santiago de Chile, 1998, p. 76.
} 
corporación al ordenamiento chileno ${ }^{3}$. Por último, otro estudioso lo ha citado en relación con el derecho a la igualdad, entre las fuentes de diferenciaciones por clases o categorías de contribuyentes (junto al principio del beneficio y el del origen de la renta), es decir, desde una perspectiva meramente económica o hacendística ${ }^{4}$.

Como he afirmado en otros lugares, para la doctrina española (orientada por la italiana y la alemana) los principios materiales de la tributación (también denominados principios de justicia tributaria) se encuentran interrelacionados y entre ellos el de capacidad económica constituye su principio rector, en términos tales que podría sintetizarse del siguiente modo (por cierto, es una exagerada simplificación, pues constituyen cuestiones de gran complejidad que han sido objeto de intensos debates): todos tienen el deber de contribuir al sostenimiento de los gastos públicos en términos de igualdad, y la medida de la igualdad es la capacidad económica -que puede implicar la progresividad en el impuesto-, la que a su vez presente un límite mínimo -zona de inmunidad fiscal, donde se entiende que se carece de capacidad económica (riqueza disponible)-cual es el mínimo existencial y un límite máximo, constituido por la prohibición de confiscatoriedad (donde un tributo que viola la capacidad económica constituye un tributo confiscatorio).

La norma esencial en el Derecho español (pero no la única) está constituida por el artículo 31.1 de la Constitución española (CE, en adelante):

Artículo 31.1. Todos contribuirán al sostenimiento de los gastos públicos de acuerdo con su capacidad económica mediante un sistema tributario justo, inspirado en los principios de igualdad y progresividad que, en ningún caso, tendrá alcance confiscatorio.

Artículo 31.2. El gasto público realizará una asignación equitativa de los recursos públicos y su programación y ejecución responderán a los criterios de eficiencia y economía.

En otra publicación, he sostenido que la interrelación de los principios de justicia tributaria exige que al estudiar el principio de capacidad económica se deban analizar los demás principios materiales de la tributación y, de modo global, el deber de contribuir. En tales materias, remito al lector a dicha publicación ${ }^{5}$.

\footnotetext{
${ }^{3}$ Nogueira Alcalá, Humberto, "La igualdad ante los tributos en el derecho constitucional chileno", Revista de Derecho y Jurisprudencia, 2008, disponible En: Base de datos http://www.microjuris.cl. Identificador del Documento: MJD277 [visitado el 12/11/2009], passim.

${ }^{4}$ Aste, Christian, Curso de Derecho y Código Tributario, 2a edición, Santiago, LexisNexis, 2006, pp. 10 y ss.

${ }^{5}$ Masbernat, Patricio, "El principio de capacidad económica como principio jurídico material de la tributación (III): Su elaboración doctrinal en España a partir de su relación con los otros principios de justicia tributaria", de pronta publicación.
} 
El presente artículo tiene por objeto abordar, de manera monográfica, el principio de capacidad en el ordenamiento español, como una de las etapas para evaluar la incorporación del indicado principio en el ordenamiento chileno.

\section{LA CAPACIDAD ECONÓMICA O CONTRIBUTIVA}

Antes de comenzar a estudiar este principio conforme al estado actual en el ordenamiento español, creo necesario dar cuenta de algunas otras cuestiones que deben ser informadas previamente.

En primer término, es conveniente recordar que no siempre en España se consideró al principio de capacidad económica como un principio con características propiamente jurídicas. En efecto, en su origen se le trataba sólo desde la perspectiva de la ciencia de la Hacienda Pública y, debido a ello, el rigorismo positivista evitó incorporarlo al mundo del Derecho por entenderlo como un concepto parajurídico ${ }^{6}$. Con el tiempo esto fue cambiando, sobre todo por la influencia del Derecho Comparado (especialmente de Italia y Alemania), y luego se le dio una configuración científica propiamente nacional en razón de su incorporación como norma en la Constitución de 1978, pues al estar consagrado en ella, se estimó que, indubitablemente, debía ser tratado como parte del Derecho vigente.

Otro asunto que debe mencionarse es que, si bien gran parte de la doctrina ha puesto de relieve la importancia de este principio (al punto de ver en éste un derecho fundamental), hay quien niega su relevancia, y otros se encuentran en un punto medio ${ }^{7}$.

Frente a esta disputa, y luego de estudiar la institución, me surge la personal convicción de la utilidad del principio de capacidad económica con independencia de los pronunciamientos particulares del Tribunal Constitucional Español (TCE, en adelante), en los cuales algunos autores pretenden ver la debilidad del principio en su funcionamiento jurídico. Más allá de la crítica acerca de su operatividad como criterio para juzgar la constitucionalidad o inconstitucionalidad de determinadas normas, su relevancia se encuentra en que genera una profunda repercusión en el debate jurídico, impacta al resto de principios materiales de la tributación (lo que por cierto ha sido recíproco), y a partir de esas reflexiones de la doctrina (basada en la norma constitucional) se ha ido

\footnotetext{
${ }^{6}$ Mongay I Soler, M, "Aplicabilidad del principio de capacidad económica como fuente material del Derecho en la jurisprudencia", Revista Española de Derecho Financiero № 87, 1995.

${ }^{7}$ Gabriel Casado Ollero sostiene que es tan inútil enfatizar la importancia de este principio como negarle toda relevancia para decidir la justicia constitucional de los impuestos. Argumenta que la capacidad económica se concreta en claras limitaciones y directrices para enjuiciar la legitimidad constitucional de las normas legales. CASADO Ollero, Gabriel, "El principio de capacidad y el control constitucional de la imposición indirecta (II). El contenido constitucional de la capacidad económica", Revista Española de Derecho Financiero № 34, 1982, p. 185.
} 
produciendo una dogmática o cuerpo sistemático de ideas con importantes consecuencias jurídicas para la defensa de la posición jurídica de los contribuyentes frente al Estado en su labor de configuración del sistema tributario. Esto ya constituye un valor en sí mismo, con independencia de si el TCE ha logrado, o no, configurar una idea clara y plenamente operativa del principio que haya traído como directa consecuencia la expulsión de alguna norma del ordenamiento jurídico.

Se ha argumentado que esta limitada virtualidad del principio de capacidad económica se produciría porque la Constitución española contiene demasiados principios de intervención del Estado en la economía (en virtud de la existencia de principios liberales y "socializantes" ${ }^{8}$ ), lo que ocasiona una mediatización o excesiva modulación del principio de capacidad económica frente a fines extrafiscales ${ }^{9}$.

Este marco normativo no existe en la Constitución chilena, o al menos no de un modo tan marcado o enfático. Por tal motivo, yo defiendo que en nuestro país este principio presenta una mayor fuerza o virtualidad jurídica. De este modo, evalúo que, en nuestro sistema, el legislador tiene una menor posibilidad de modularlo al configurar el sistema tributario ${ }^{10}$, al encontrarse -en teoríaespecialmente vinculado a derechos fundamentales, tales como el derecho de propiedad y una serie de derechos que apuntan a favorecer la actividad de los emprendedores $y$, además, porque se encuentran mucho más restringidos los fines de contenido social que el Estado debe concretar (directrices, bienes constitucionalmente tutelados, intereses colectivos) ${ }^{11}$.

Por cierto que creo que el Estado debe sustentar su actuar en irrenunciables exigencias éticas, como la solidaridad, pero de ello no se sigue que deba

${ }^{8}$ Alguacil Marí, María Pilar, "Capacidad económica como parámetro de enjuiciamiento", Revista de Derecho Financiero y Hacienda Pública No 253, 1999, p. 591. Lo que podríamos Ilamar las "dos almas" de la Constitución Española.

${ }^{9}$ A juicio de Palao Taboada, la legislación con fines extrafiscales es el principal escollo al principio de capacidad económica. Desde una cierta perspectiva, el legislador puede perseguir cualquier finalidad distinta, siempre que no actúe de manera arbitraria. PalAO TABOADA, Carlos, "Apogeo y crisis del principio de capacidad contributiva", Estudios jurídicos en homenaje al profesor Federico de Castro, Vol. II, 1976, p. 418.

${ }^{10}$ Ello, puesto que el Estado es menos "libre" -si bien técnicamente nunca debiera caber esta expresión- en su actuar frente al particular.

${ }^{11}$ En interesante la opinión de Alguacil Marí, en el sentido de estimar como base del problema que el principio de capacidad económica ha tenido en su aplicación (lo llama "funcionamiento dual") se debe a esta convivencia de las "dos almas" en la CE -liberal socializadora-, que hace que el principio de capacidad económica (y el de igualdad) presenten un fundamento mixto (y una doble función), presentando, por un lado, el carácter de principio en sentido restringido (con finalidad garantística, como derecho) y, por otro lado, el carácter de directriz (por estar basada en el principio de solidaridad, dando fundamento a las funciones de promoción y redistribución llevadas a cabo por el Estado Social). AlguaClL, "Capacidad", cit. nota n. 8, pp. 591 y 604 y ss. 
concretarlas, necesariamente, a través del tributo (limitando, restringiendo o vulnerando principios materiales tributarios) o de la directa actividad planificadora del Estado (vulnerando el despliegue de la libertad y la personalidad). Existen otras vías por las cuales la sociedad puede concretar el bien común, entre ellas, el desarrollo de las propias virtudes cívicas y sociales por parte de los individuos.

Por otro lado, cabe sostener que el principio de capacidad económica no es el único principio de justicia tributaria, y ello no le resta ni importancia ni autonomía conceptual. El valor de este principio lo expone muy bien Casado Ollero cuando destaca que "es un factor que en nuestra actual perspectiva histórica y socio-cultural, habrá necesariamente que tenerse en cuenta para que la ordenación impositiva, aparezca o no expresamente formulada en el texto constitucional", y que su vinculación al concepto de tributo es tal que responde a la naturaleza misma de las $\operatorname{cosas}^{12}$.

Quienes niegan a la capacidad económica el carácter de principio con contenido y vigencia intrínsecos, lo acusan de vago e impreciso, que no entrega claros criterios para enjuiciar las normas ${ }^{13}$, le otorgan exclusivamente un carácter de "lo razonable" en el juicio de constitucionalidad ${ }^{14}$ dentro del principio de igualdad, o con efectos muy restringidos (negativos) en el ámbito jurídico ${ }^{15}$ y únicamente como límite al legislador ${ }^{16}$. Desde tal perspectiva, su fin sería político y no jurídico, por cuanto de este principio no sería posible obtener directrices operativas a fin de diseñar el sistema tributario o cada impuesto en particular. Sin embargo, parece más adecuado suponer que los problemas que este principio enfrenta son semejantes al de los demás principios materiales $(y$,

${ }^{12}$ CASAdO, "El principio", cit. nota n. 7, p. 187.

${ }^{13}$ Casado Ollero sostiene que el principio de capacidad económica poner de manifiesto, en caso de su vulneración, la existencia de una arbitrariedad en la actuación del legislador, y no tiene por función fundar sentencias de inconstitucionalidad. Cuando el poder público infringe el principio de capacidad económica, se vulneran los derechos de propiedad -a través de las detracciones que afecten el mínimo existencial o tengan efectos confiscatorios -o de igualdad- por el tratamiento fiscal discriminatorio injustificado-. CASADO, "El principio", cit. nota n. 7, pp. 197 y 205.

${ }^{14}$ En interpretación de María Pilar Alguacil Marí, en AlguaCIL, "Capacidad", cit. nota n. 8.

${ }^{15}$ Casado Ollero claramente se encuentra distante de la opinión de Palao Taboada cuando explica que los mandatos constitucionales se operacionalizan a través de dos vías: (a) como elementos de los presupuestos de cada tributo, de modo que su ausencia impide el surgimiento de la obligación tributaria; (b) como elementos condicionantes de la imposición, de modo que su ausencia impida la exigibilidad o eficacia de la obligación que surge por la realización del presupuesto del tributo (CASADO, "El principio", cit. nota n. 7, p. 206). Que posea o no criterios operativos o directrices de solución de problemas, no implica todo sobre sus efectos, ya que, por ejemplo, el Estado (Legislativo, Ejecutivo) no podrá establecer criterios de imposición opuestos a la capacidad económica (CASADO, "El principio", cit. nota n. 7, p. 223).

${ }^{16}$ Palao Taboada, Carlos, "Nueva visita al principio de capacidad contributiva", Revista Española de Derecho Financiero No 124, 2005, p. 769. 
en general, a cualquier principio constitucional), pero no por dicha razón éstos carecen de relevancia.

\section{Fundamentos normativos}

De acuerdo he informado, la CE lo consagra en el artículo 31.1 como principal criterio de la estructura tributaria ${ }^{17}$. Debe, asimismo, considerarse el artículo 31.2 que lo vincula con el gasto fiscal ${ }^{18}$.

Asimismo, es reconocido en la Ley General Tributaria (58/2003) aunque, a juicio de algunos autores, bajo un carácter algo distinto ${ }^{19}$ :

3.1. La ordenación del sistema tributario se basa en la capacidad económica de las personas obligadas a satisfacer los tributos y en lo principios de justicia, generalidad, igualdad, progresividad, equitativa distribución de la carga tributaria y no confiscatoriedad.

No sólo en el Derecho Español de origen interno es posible encontrar el fundamento normativo de este principio ${ }^{20}$, ya que tiene expresión en el Convenio Europeo de Derechos Humanos como consecuencia de lo dispuesto en su artículo 14 (igualdad y no discriminación por razón del patrimonio) y en el artículo 1 del Protocolo 1 (derecho de propiedad); en los Tratados de las Comunidades Europeas (artículos 12, 18, 39, 43, 49, 56, 87) y de la Unión Europea $^{21}$ (artículo 6, que garantiza el respeto de los derechos humanos, según

\footnotetext{
${ }^{17}$ Medina Guerrero, Manuel, "Las Obligaciones Tributarias", disponible En: Base de datos http://www. iustel.es. Identificador del documento RI §910504, [visitado el 06/11/2009].

${ }^{18}$ La esencial vinculación entre ingresos y gastos públicos en el contexto de un sistema financiero justo ha sido destacada por diversos autores y por el propio TCE (STCE 76/1990, de 26 de abril). En vinculación al principio preciso que es objeto de este estudio, Fernández Segado ha dicho que "el principio de capacidad económica, regla nuclear en el reparto y distribución de la carga tributaria, debe combinarse estrechamente con los principios de justicia en el gasto público" (Fernández Segado, Francisco, "El diseño constitucional del deber de contribuir al sostenimiento de los gastos públicos", Revista Vasca de Administración Pública. Herri-Arduralaritzako Euskal Aldizkaria № 47, 1, 1997, p. 81). Esta relación también es destacada por otros autores. Cfr.: AtBIñana García-Quintana, César, "El gasto público", en Alzaga Villamil, Oscar (coord.), Comentarios a la Constitución Española de 1978, Tomo III, Cortes Generales-Editoriales de Derecho Reunidas, Madrid, 1996, p. 412.

${ }^{19}$ Eseverri sostiene que la referencia a que el tributo debe procurar la equitativa distribución de la carga tributaria constituye no un principio de contenido jurídico, sino un criterio hacendístico en el reparto de la carga fiscal. Véase: EsEVERRI, Derecho, cit. nota n. 1, p. 27.

${ }^{20}$ Que ha dado origen a diversos pronunciamientos del Tribunal Constitucional Español, entre ellas, las sentencias 57/2005, 164/2005, conforme recuerda Pedro Herrera Molina.

${ }^{21}$ En razón de ello, se han dictado sentencias en relación al principio de capacidad económica por el Tribunal Europeo de Derechos Humanos (de fecha 19 de julio de 2005, 6638/03, P.M. con Reino Unido) y por el Tribunal Europeo de Justicia (caso Schemp, 403/03, 12 de julio de 2005; caso Turpeinen C-520-04, 9 de noviembre de 2006).
} 
el Convenio Europeo de Derechos Humanos y las tradiciones constitucionales comunes a los Estados miembros) ${ }^{22}$.

\section{Concepto y elementos}

La capacidad económica dice relación con la potencialidad económica vinculada a la titularidad y disponibilidad de la riqueza ${ }^{23}$; con la aptitud, la posibilidad real, la suficiencia de un sujeto de derecho para hacer frente a la exigencia de una obligación tributaria concreta por parte de una Administración Pública ${ }^{24}$.

Este principio, conforme a la mayor parte de la doctrina consultada, es entendido de múltiples maneras, a saber: como la regla material básica de reparto o distribución de las cargas públicas ${ }^{25}$; principio rector de la justicia tributaria; el más calificado criterio material para la distribución justa de los impuestos ${ }^{26}$; el fundamento, justificación y medida del tributo; el criterio de unidad del concepto mismo de tributo, etc.

Se ha distinguido entre la capacidad económica absoluta y la relativa ${ }^{27}$ : dos facetas de un mismo fenómeno, como se verá.

La primera es concebida como la capacidad abstracta para concurrir al sostenimiento de las cargas públicas. Se trata de aquella capacidad que se tiene presente al determinar el supuesto de hecho base del tributo (entre ellos, titularidad de un patrimonio y percepción de una renta como índices directos de manifestación de riqueza; el consumo de bienes y el tráfico o la circulación de la riqueza como índices indirectos), y garantiza que únicamente se establezcan tributos sobre actos, hechos o negocios indicativos de capacidad económica ${ }^{28}$

\footnotetext{
${ }^{22}$ Herrera Molina, Pedro Manuel, "El Principio de Capacidad Económica", disponible En: Base de datos de http://www.iustel.es Identificador de documento RI §910978 [visitado el 16/11/2009].

${ }^{23}$ Fernández, "El diseño", cit. nota n. 18, p. 98. Para Carrera Raya, capacidad económica es un término más adecuado que el de capacidad contributiva, la cual es una calificación hecha por el legislador. Ver, Carrera Raya, José Francisco, Manual de Derecho Financiero, Vol. I, Derecho Financiero y Teoría de los Ingresos Públicos, Tecnos, Madrid, 1994.

${ }^{24}$ Calvo Ortega, Rafael, Curso de Derecho Financiero, I. Derecho Tributario, Parte General, $10^{\text {a }}$ edición, Thomson-Civitas, Madrid, 2006, p. 52.

${ }^{25}$ FernándeZ, "El diseño", cit. nota n. 18, p. 96.

${ }^{26}$ Albiñana, "El gasto público", cit. nota n. 18, p. 7.

${ }^{27}$ Distinción que interpreto como análoga a la de Casado Ollero, entre capacidad económica como, por un lado, fuente de la imposición y, por otro, como criterio de contribuir al sostenimiento de los gastos públicos. Ver, CASADO, "El principio", cit. nota n. 7.

${ }^{28}$ Collado Yurrita, Miguel Ángel; Moreno González, Saturnina, "Tema 2: Principios constitucionales del Derecho Tributario", en Collado YurRita, Miguel Ángel (director); Luchena Mozo, Gracia María (coord.), Derecho Tributario, Parte General, 2ª edición, Madrid, Editorial Atelier, 2007, p. 38.
} 
en consideración a que son representaciones de la riqueza (es un límite del tributo, pues sólo puede tributar la riqueza y sólo ella).

Conforme a la idea de normalidad, el hecho imponible es normalmente expresión de capacidad, pero como en determinadas situaciones concretas ello no sucede, en tales casos debieran existir exenciones o bonificaciones y no exclusiones a priori como norma general, por lo que la generalidad encuentra excepciones (STCE 46/2000) ${ }^{29}$. De esta manera, este criterio material exige respetar un mínimo existencial como espacio exento de carga fiscal. Por el contrario, se encuentra en fricción frente a las situaciones de doble imposición interna, con las exenciones sin justificación constitucional, al gravamen de incrementos monetarios nominales ${ }^{30} \mathrm{o}$ adquisiciones instrumentales ${ }^{31}$.

Desde esta perspectiva, este principio constituye la razón de ser (la ratio) o fundamento que justifica el hecho mismo de contribuir (y la exigencia de cumplir este deber constitucional), es la base del tributo (como lo es el principio del beneficio en las tasas y contribuciones especiales; si bien la capacidad económica se extiende a todos los tributos, incluidos éstos ${ }^{32}$ y, por tanto, constituye el elemento indisociable de la tipificación legal impositiva que legitima constitucionalmente el tributo. De ahí, se sostiene que se debe porque se tiene capacidad económica para soportar el gravamen tributario ${ }^{33}$. Es el punto de partida sobre el cual se construye un sistema tributario justo, por ello es un principio con claro carácter ético ${ }^{34}$.

\footnotetext{
${ }^{29}$ Queralt, Martín; Lozano, Carmelo; Tejerizo, José; Casado, Gabriel, Curso de Derecho Financiero y Tributario, 18ª edición, Tecnos, Madrid, 2007, p. 124.

${ }^{30}$ Pero esto no ha estado exento de problemática, que Falcon y Tella describe con ocasión del comentario a la Ley de IRF 40/1998, de 20 de diciembre (BOE 10 diciembre 1998, QF 22/98), por no tener en cuenta en absoluto la corrección monetaria (el factor inflación) respecto de ciertos elementos patrimoniales, y por no habilitar siquiera al reglamento para introducir medidas correctoras, lo que resulta claramente inconstitucional, por cuanto, como ha sostenido el TCE la existencia de coeficientes correctores "responde a la naturaleza del impuesto sobre la renta, que ha de contemplar incrementos reales no monetarios" (STCE 20 julio 1981, FJ 6), y como sostuvo, no obstante la flexibilización introducida en esta materia, la STCE 221/1992, de 11 diciembre, en relación con el Impuesto Municipal sobre incremento del Valor de los Terrenos, donde afirmó que, si bien el principio de capacidad contributiva no implica la obligatoriedad de practicar en todo caso correcciones monetarias "tampoco permite al legislador desconocerlo por completo, siempre que la erosión inflacionaria sea de tal grado que haga inexistente o ficticia la capacidad económica gravada por el tributo". FALCón Y TELLA, Ramón, "El nuevo IRPF y la capacidad contributiva (II): coeficientes de corrección monetaria y rendimientos irregulares", Quincena Fiscal Aranzadi № 2, 1999, disponible En: Base de datos http://www.westlaw. es Identificador del documento BIB 1998\1313 [visitado el 27/10/2009].

${ }^{31}$ Calvo, Curso, cit. nota n. 24, p. 52.

${ }^{32}$ Calvo, Curso, cit. nota n. 24, p. 52.

${ }^{33}$ RodríGUez BeREIJO, Álvaro, "Jurisprudencia constitucional y principios de la imposición", disponible En: Base de Datos http://www.tirantonline.com Identificador del documento TOL314.024 [visitado el 03/11/2009].

${ }^{34}$ AlbiñAna, "El gasto público", cit. nota 18, p. 412.
} 
Este principio, en la función de regular la carga tributaria, es básico para la producción de normas tributarias, también, en su carácter de límite al legislador $^{35}$, pues lo obliga a construir un sistema tributario y unos tipos impositivos congruentes con sus criterios ${ }^{36}$, es decir, que graven sus manifestaciones reales (obtención de una renta) o potenciales (disfrute de una propiedad, como la vivienda), en términos de imponer la obligación de acuerdo a índices significativos de capacidad económica (la renta en la medida que se obtiene, el patrimonio en la medida que se posee, el consumo en la medida que se realiza); e impide intentar gravar riquezas ficticias o inexistentes ${ }^{37}$.

Por su parte, la capacidad económica relativa es concebida como aquella capacidad que orienta o modula la concreta carga tributaria que un contribuyente debe soportar. Constituye la medida, razón o proporción de cada contribución individual de los sujetos obligados al sostenimiento de los gastos públicos, pues se debe de acuerdo o según a la capacidad que se tiene, ${ }^{38}$ lo cual debe reflejarse en el hecho imponible y en los elementos esenciales que determinan la cuantificación de la deuda tributaria ${ }^{39}$.

Estas categorías pueden ser reelaboradas afirmando que la capacidad económica siempre debe estar presente a fin de condicionar que el hecho impositivo sea indicativo de ella; pero, además, que la carga impositiva individual, i.e., de cada contribuyente, no debe superar el límite imponible de acuerdo a este mismo principio ${ }^{40}$.

Una de las dificultades operativas del principio capacidad económica, principio de justicia que constituye presupuesto y límite de la legislación tributaria, es su imposibilidad de petrificarlo en fórmulas fijas.

\footnotetext{
${ }^{35}$ Calvo, Curso, cit. nota n. 24, p. 52. Palao Taboada niega relevancia al principio de capacidad económica, señalando que el principio de capacidad económica "desde la perspectiva estrictamente jurídica... tiene la función relativamente modesta de límite al legislador: una función esencialmente negativa de resistencia al poder". PALAO, "Nueva vista", cit. nota n. 16, p. 769.

${ }^{36}$ Así lo ha declarado el Tribunal Constitucional. STCE 96/2002, de 25 de abril, FJ 7º: "Esta recepción constitucional del deber de contribuir al sostenimiento de los gastos públicos según la capacidad económica de cada contribuyente configura un mandato que vincula no sólo a los ciudadanos sino también a los poderes públicos (STC 76/1990, de 26 de abril, F. 3) ya que, si los unos están obligados a contribuir de acuerdo con su capacidad económica al sostenimiento de los gastos públicos, los poderes públicos están obligados, en principio, a exigir esa contribución a todos los contribuyentes cuya situación ponga de manifiesto una capacidad económica susceptible de ser sometida a tributación.". Véase también: STCE 76/1990, de 26 de abril, FJ 3º.

${ }^{37}$ EseVERRI, Derecho, cit. nota n. 1, p. 29.

${ }^{38}$ Rodríguez, "Jurisprudencia", cit. nota n. 33.

${ }^{39}$ Collado; Moreno, "Tema 2:", cit. nota n. 28, p. 38; Sainz de Bujanda, Fernando, Lecciones de Derecho Financiero, $5^{\mathrm{a}}$ edición, Universidad Complutense de Madrid, Facultad de Derecho, Madrid, 1991, p.107.

${ }^{40}$ CASADO, "El principio", cit. nota n. 7, p. 221.
} 


\section{Estructura}

Desde el punto de vista del ideal de los valores jurídicos, la capacidad económica puede definirse como la riqueza disponible de un sujeto, y su contenido debiera exigir tres extremos ${ }^{41}$ :

(a) El principio del neto objetivo (estimación objetiva, capacidad objetiva), el cual exige que sólo tribute la renta neta y no las sumas destinadas a obtener los ingresos, de modo tal que la carga tributaria global sea función de la capacidad económica de cada contribuyente.

(b) El principio del neto subjetivo (capacidad subjetiva) o de exoneración del mínimo existencial personal y familiar (de las personas físicas o naturales) ${ }^{42}$, que dispone que no debe tributarse por las cantidades necesarias para garantizar al contribuyente y a su familia una vida digna ${ }^{43} y$, en tal sentido, el tributo debe configurarse conforme a la riqueza disponible en función de las circunstancias personales y familiares. El mínimo exento personal refleja una riqueza no disponible que tiene por fin garantizar una existencia mínimamente digna ${ }^{44}$.

(c) Determinación de la intensidad del gravamen, que implica que éste debe conformarse a la riqueza disponible, y en cuanto tal, procede la tributación progresiva, pero sujeta al límite de la no confiscatoriedad.

También debe considerarse como parte del principio de capacidad económica el principio de tributación de la riqueza efectiva, que exige que sólo tribute la riqueza real y no los rendimientos ficticios o nominales. Con todo, el TCE ha decidido que no sólo debe tributar la riqueza o renta real, sino, también, la riqueza potencial (STCE 37/1987).

\footnotetext{
${ }^{41}$ Herrera, "El Principio", cit. nota n. 22.

${ }^{42}$ Respecto de las personas jurídicas, Herrera Molina (ib.) agrega que "no cabe hablar de un derecho a contribuir con arreglo a la capacidad económica 'subjetiva', pero sí de una capacidad objetiva plasmada en la disponibilidad de la renta neta. En la medida en que esta riqueza no resulte disponible para determinadas personas físicas, constituye una capacidad económica objetiva de la persona jurídica que debe someterse a tributación. Además, el principio de capacidad económica exige adoptar medidas para evitar fenómenos de doble imposición."

${ }^{43}$ Sobre el mínimo exento familiar, el Tribunal Constitucional Alemán ha dicho que "el Estado debe exonerar la renta del contribuyente en cuanto ésta sea necesaria para lograr las condiciones mínimas que requieran una existencia humana digna" (sentencia de 29 de mayo de 1990). En otra sentencia, este mismo órgano constitucional ha exigido que el mínimo exento previsto por la ley -que calcula sumando reducciones fiscales y subvenciones por hijos- no puede fijarse por debajo de las cantidades previstas en los subsidios sociales para personas indigentes; y dicho mínimo exento debe garantizarse aun a aquellos individuos que obtienen rentas por encima del mínimo existencial a objeto de garantizar un trato no discriminatorio (sentencia de 12 de junio de 1990). Citado en Herrera Molina, Pedro Manuel, "El principio de capacidad económica en Alemania y su relevancia para el derecho español", Noticias de la Unión Europea № 150, 1997, p. 39.

${ }^{44}$ Herrera, "El principio", cit. nota n. 43, p. 39.
} 


\section{Principio de capacidad económica y el mínimo existencial}

Como he puesto de manifiesto, una categoría esencial vinculada al principio de capacidad económica es la del mínimo existencial (también denominado mínimo vital, mínimo exento, mínimo de sobrevivencia, mínimo imponible, mínimo no imponible, procura existencia ${ }^{45}$ ) que encuentra su raíz en el reconocimiento de la dignidad de la persona humana y en la protección de la familia, y que constituye un mínimo ético derivado de la justicia tributaria y un mínimo lógico que evita la arbitrariedad legislativa ${ }^{46}$. Por ello, beneficia a las personas físicas (naturales) ${ }^{47}$ aunque, en ciertos casos, puede encontrar lugar en la tributación de personas jurídicas por ser una extensión de la personalidad humana. Se trata de un espacio de indemnidad fiscal, i.e., asienta un elemento de individualización por cuanto la aptitud para contribuir a los gastos públicos sólo comienza cuando se han cubierto las necesidades mínimas personales y familiares.

En virtud de este criterio, no toda titularidad de riqueza supone capacidad para contribuir, pues su inexistencia implicaría la desaparición física del contribuyente ${ }^{48}$.

El mínimo vital o existencial se ha conceptualizado como aquel conjunto de recursos económicos que en una unidad de tiempo permite atender las necesidades elementales personales y familiares ${ }^{49}$; o como la cantidad que no puede ser objeto de gravamen, por cuanto la misma se encuentra afectada a la satisfacción de las mínimas necesidades vitales de su titular ${ }^{50}$.

Únicamente a partir de ahí comienza la capacidad económica para atender a las obligaciones fiscales. Esta franja mínima de recursos para la existencia recibe cobertura no sólo a través de la tributación sino también mediante ayudas públicas (es decir, son expresiones tanto de la vertiente del ingreso público

\footnotetext{
${ }^{45}$ Gallego Peragón, José Manuel, Los principios materiales de justicia tributaria, Comares, Granada, 2003, p. 106.

${ }^{46}$ CASAdO, "El principio", cit. nota n. 7, p. 231.

${ }^{47}$ FalCón Y TelLa recuerda que "En todo caso, el mínimo exento y otras exenciones técnicas se han visto siempre como una consecuencia de la capacidad contributiva, que desde las primeras construcciones jurídicas de este principio (Giardina) se entiende como la exigencia de gravar sólo la renta actual, neta, individual y disponible." Falcón Y TelLA, Ramón, "Exenciones y capacidad contributiva: la paradoja de la exención de los bienes necesarios para el desarrollo de actividades empresariales", Quincena Fiscal Aranzadi $\mathrm{N}^{\circ}$ 7, 1995, disponible En: Base de datos http://www.westlaw.es Identificador del documento BIB 1995\1249 [visitado el 27/10/2009].

${ }^{48}$ Gallego, Los principios, cit. nota n. 45, p. 111.

${ }^{49}$ Calvo, Curso, cit. nota n. 24, p. 53.

${ }^{50}$ Queralt; Lozano; Tejerizo; Casado, Curso, cit. nota n. 29, p. 126.
} 
como de la del gasto público). Dichas cantidades establecerían la existencia de capacidad económica, pero no de capacidad contributiva.

Es impracticable fijar una cantidad determinada para dicho mínimo, pues éste variará de tiempo y lugar, y dependerá de las opciones políticas (que define la configuración del Estado y su sistema financiero, si es Estado Social o Liberal), aunque se la ha vinculado al monto de ayudas públicas a personas sin recursos o a lo necesario para la existencia conforme al esquema de derechos económicos y sociales constitucionalmente consagrados ${ }^{51}$. Se han derivado múltiples reglas operativas, entre ellas, que no debe someterse a tributación a los beneficiarios de las ayudas sociales y menos en virtud de recibir éstas ${ }^{52}$.

Entre las técnicas para satisfacer este mínimo vital, se encuentra la cuota tributaria cero hasta cierto límite, deducciones específicas (deducciones familiares, coberturas de los gastos por enfermedad, bonificaciones por la constitución de rentas futuras, ayudas fiscales para la adquisición de viviendas o pago de arrendamientos, exención al consumo de productos de primera necesidad, servicios públicos gratuitos, etc.), o la deducción de una cantidad global o sintética en el impuesto que grava la renta de las personas ${ }^{53}$.

Se ha destacado que en un Estado Social (como España) el mínimo existencial tiene menos sentido que en un Estado Liberal, debido a que en el segundo

\footnotetext{
${ }^{51}$ Para FalCon y Tella constituye una exigencia constitucional, que formula en los siguientes términos: "es arbitrario (y por tanto inconstitucional) el gravamen de la renta que no supere la cuantía que el Estado facilita a otros sujetos a través de pensiones no contributivas, ayudas para la adquisición de vivienda, por hijos, etc. Obviamente es difícil medir el nivel de las ayudas o subvenciones públicas que deben computarse (y que en el caso español, además, varían de una Comunidad a otra). Pero en todo caso, esa renta básica que a algunos se subvenciona de una u otra manera, debe quedar exenta de tributación para todos". Asimismo, cita la sentencia del Tribunal constitucional alemán, de 25 de septiembre de 1992, que decidió que "la cuantía del mínimo existencial depende de la situación económica general y de la necesidad mínima reconocida por la comunidad jurídica. El valorar estas circunstancias corresponde al legislador, pero en cuanto éste ha determinado las necesidades mínimas en la regulación de las ayudas sociales... el mínimo exento no puede ser inferior a la mencionada cifra" (FALCón y TeLLA, "El tipo único (flat tax) en el IRPF y la sorprendente propuesta de tipos progresivos en el IBI). Quincena Fiscal Aranzadi $\mathrm{N}^{\circ} 20$, 2004, disponible En: Base de datos http://www.westlaw.es Identificador del documento BIB 2004 1757 [visitado el 27/10/2009]). Este autor, en otro sitio, recuerda que "el mínimo exento no plantea sólo el problema de su articulación en la cuota o en la base imponible, sino también el problema de su cuantía, para cuya concreción cabe atender al salario mínimo interprofesional, o bien a las prestaciones sociales no contributivas, pues, al margen de la discrecionalidad que ciertamente ha de reconocerse al legislador en este punto en función de la situación económica general, es indudable que tal discrecionalidad es perfectamente controlable a través de la 'necesidad mínima reconocida por la comunidad jurídica', en el sentido de que cuando el legislador ha determinado las necesidades mínimas a través de la regulación de las ayudas sociales, el mínimo exento no puede ser inferior a la mencionada cifra" (Falcón y Tella, Ramón, "El nuevo IRPF y la capacidad contributiva (I): mínimo personal y familiar e individualización de rentas", Quincena Fiscal Aranzadi No 1, 1999, disponible En: Base de datos http://www.westlaw.es Identificador del documento BIB 1998\1137 [visitado el 27/10/2009]).

${ }^{52}$ CASADO, "El principio", cit. nota n. 7, p. 192.

${ }^{53}$ Calvo, Curso, cit. nota n. 24, p. 53.
} 
las economías individuales deben dar cobertura a estas necesidades vitales. Sin embargo, es en los Estados sociales donde encuentra un mayor desarrollo. Esto tiene múltiples razones, entre ellas, que en los Estados liberales se exige mayor responsabilidad individual por los actos que cada uno decide en su vida; hay más libertad y más responsabilidad. En los Estados sociales hay menos libertad y menos responsabilidad, en el entendido que es el Estado el que cobija muchas veces con independencia del actuar (del merecimiento) de las personas. Con todo, el mínimo existencial no sólo se ancla en la idea de solidaridad social, sino, asimismo, en la de capacidad económica en cuanto riqueza disponible, y responde a la propia naturaleza de las cosas y a la idea de justicia, de libertad, de tributación mínima, de respeto por la libertad, de derecho de propiedad e incluso, del propio derecho a la vida. En definitiva, el concepto de mínimo existencial es perfectamente compatible con un Estado liberal.

Si bien, conceptualmente, el mínimo existencial no presenta problemas de justificación o plausibilidad, es posible observar ciertos problemas de operatividad. Esto es verificable por medio de la distinción entre sus aspectos objetivo y subjetivo. Desde un punto de vista objetivo, se refiere al nivel de renta que por su cuantía carece de capacidad contributiva (que encuentra su expresión más típica en límites mínimos de renta exentos de tributación). El enfoque subjetivo atiende al contribuyente en relación a sus propias circunstancias, "al coste de su propia supervivencia" ${ }^{\prime 54}$. Ambos aspectos son relevantes, no uno solo de ellos, con independencia del aspecto que en cada caso la legislación o la doctrina considere con mayor peso específico.

\section{5. Ámbitos de actuación del principio}

Para su correcto análisis, entre otras cosas, debe distinguirse los ámbitos de aplicación de este principio: subjetivo, territorial y temporal. ${ }^{55}$

En el ámbito subjetivo de aplicación, se entiende que los titulares del derecho a contribuir conforme a su capacidad económica son únicamente las personas físicas o naturales, en razón de que este derecho surge de la dignidad humana, y se vincula al mínimo existencial personal y familiar. A las personas jurídicas les caben efectos limitados, no menos relevantes, en virtud de los cuales su obligación de tributar debe recaer en su riqueza disponible conforme a la renta neta y, además, que el Estado debe adoptar medidas para evitar la doble imposición. El TCE ha afirmado

\footnotetext{
54 FERNÁNDEZ, "El diseño", cit. nota n. 18, p. 99.

${ }^{55}$ Gorospe Oviedo, Juan Ignacio; Herrera Molina, Pedro Manuel, "La virtualidad del principio de capacidad económica en el ordenamiento tributario español", en Albiñana García-Quintana, César; González García, E.; Ramallo Massanet, Juan; Lejeune Valcárcel, Ernesto; Yábar Sterling, A., Estudios en homenaje al profesor Pérez de Ayala (coords.), Dykinson, Madrid, 2007, p. 53.
} 
que las personas jurídicas están formadas por personas físicas y en cuanto tales el sistema jurídico debe reconocerles derechos (STC 64/1988 FJ 1) ${ }^{56}$.

En el ámbito territorial, y en tanto la imposición recaiga sobre la renta global, el principio de capacidad económica genera como consecuencia el deber del Estado de evitar la doble tributación ${ }^{57}$. Existe jurisprudencia del Tribunal de Justicia de la Comunidad Europea en la que el principio de capacidad económica encuentra reflejo en el debate judicial acerca del derecho de no discriminación y de las libertades comunitarias de circulación y establecimiento ${ }^{58}$.

En el ámbito temporal, si bien se admite la posibilidad de implantar normas tributarias retroactivas por parte del legislador, pues de otro modo se impide toda reforma fiscal sustantiva, se ha sostenido que la capacidad económica debe referirse a aquella ínsita en el presupuesto del tributo y no a una pasada (STCE 126/1987) ${ }^{59}$.

\section{Su interpretación y aplicación: el juego del principio de capacidad económica en el contexto constitucional}

Una cuestión de extrema relevancia para la comprensión de este principio es el de la interpretación sistemática del principio en estudio, i.e., en el contexto constitucional global. El contenido y las fronteras del principio de capacidad económica deben construirse en el contexto constitucional, esto es, en relación a los demás principios de justicia material, a los bienes constitucionalmente tutelados, y a los fines extrafiscales del tributo, entre otros aspectos.

La doctrina tradicional en España defendió por mucho tiempo el carácter de la capacidad económica como principio definidor de la justicia tributaria ${ }^{60}$, lo que tuvo su origen en la influencia de la doctrina italiana ${ }^{61}$.

Desde muy temprano, el TCE ha destacado que este principio, no obstante constituir un límite al legislador, no es el único criterio material de justicia tributaria en España, exclusivo y excluyente, aunque sí puede serlo en otros ordenamientos (STCE 46/2000 y STCE 134/1996), y más bien aparece vinculado o debe relacionarse con otros principios del sistema tributario ${ }^{62}$ a objeto

\footnotetext{
${ }^{56}$ GorosPe; Herrera, "La virtualidad" cit. nota n. 55, p. 53.

${ }^{57} \mathrm{Al}$ respecto, ver estudio de Herrera Molina, Pedro Manuel, 'Aspectos internacionales del Impuesto sobre la Renta y capacidad económica', en VV.AA., La Justicia en el Diseño y Aplicación de los Tributos, IEF, Madrid, 2006, pp. 501-524.

${ }^{58}$ Gorospe; Herrera, "La virtualidad" cit. nota n. 55, p. 54.

${ }^{59}$ Gorospe; Herrera, "La virtualidad" cit. nota n. 55, p. 54.

${ }^{60}$ FernÁndez, "El diseño", cit. nota n. 18, p. 95.

${ }^{61}$ PALAO, "Apogeo", cit. nota n. 9.

${ }^{62}$ Especialmente aquellos más íntimamente entrelazados, a saber, igualdad, progresividad y no confiscatoriedad, los demás del artículo 31.1 CE; los de justicia del gasto público, a saber, de asignación equitativa de los recursos públicos, de eficiencia y de economía de la programación y ejecución del gasto, del artículo 31.2 CE. De ello, resulta que deben aplicarse principios de justicia tanto en materia de ingreso como de gasto público.
} 
de realizar el ideal de justicia en el reparto de la carga tributaria (en sentencia 27/1981, de 20 de julio ${ }^{63}$. Los principios tributarios del artículo 31.1 de la Constitución Española forman un sistema de reglas para el reparto individual de la carga fiscal ${ }^{64}$.

De este modo, el principio de capacidad económica se encuentra íntimamente relacionado (modula y es modulado) con los demás principios y valores incorporados en la Constitución.

Encuentra estrecha vinculación con el principio de igualdad tributaria, afirmándose que constituye la medida de la igualdad, o que es una forma de entender la generalidad o la igualdad.

Observa claros vínculos con la igualdad tributaria, la que dispone que a iguales índices de capacidad económica exista una misma presión tributaria sobre sus titulares ${ }^{65}$. Este principio también implica que debe

${ }^{63}$ STCE 27/1981, FJ 4: "A diferencia de otras Constituciones, la española, pues, alude expresamente al principio de la capacidad contributiva y, además, lo hace sin agotar en ella -como lo hiciera cierta doctrina- el principio de justicia en materia contributiva. Capacidad económica, a efectos de contribuir a los gastos públicos, significa tanto como la incorporación de una exigencia lógica que obliga a buscar la riqueza allí donde la riqueza se encuentra. / Pero el servicio de esta lógica no asegura, por sí solo, 'un sistema tributario justo, inspirado en los principios de igualdad y progresividad' que pudiera demandar la estimación individualizada de cada caso, con respecto a cada uno de los tributos que integran el sistema tributario y en cualquier supuesto en orden al sistema tributario mismo, como conjunto, atendidas las variantes circunstancias sociales y económicas".

${ }^{64}$ La importancia del valor constitucional "sistema", conforme al cual deben configurarse los tributos, ha sido puesto de manifiesto en la doctrina. Por todos: Romero García, Felipe, El valor sistema tributario: acerca de su integración entre los principios de la imposición, Servicio de Publicaciones de la Universidad de Cádiz, Cádiz, 2005.

${ }^{65}$ El Tribunal Constitucional ha puesto de relieve este vínculo en múltiples ocasiones. STCE 193/2004, de 4 de noviembre, FJ 30: "Pero aún debemos precisar más: se alega un trato desigual ante la ley tributaria. Esta precisión es relevante porque, como venimos reiterando, la igualdad ha de valorarse, en cada caso, teniendo en cuenta el régimen jurídico sustantivo del ámbito de relaciones en que se proyecte. En la materia tributaria es la propia Constitución la que ha concretado y modulado el alcance de su artículo 14 en un precepto, el artículo 31.1, cuyas determinaciones no pueden dejar de ser tenidas aquí en cuenta, pues la igualdad ante la Ley tributaria resulta indisociable de los principios de generalidad, capacidad, justicia y progresividad, que se enuncian en el último precepto constitucional citado (entre otras, SSTC 27/1981, 20 de julio [RTC 1981, 27], F. 4, y 46/2000, de 17 de febrero [RTC 2000, 46], F. 4). Efectivamente, dicho precepto constitucional dispone que "todos contribuirán al sostenimiento de los gastos públicos de acuerdo con su capacidad económica mediante un sistema tributario justo inspirado en los principios de igualdad y progresividad que, en ningún caso, tendrá alcance confiscatorio". Esta recepción constitucional del deber de contribuir al sostenimiento de los gastos públicos según la capacidad económica de cada contribuyente configura un mandato que vincula, no sólo a los ciudadanos, sino también a los poderes públicos (STC 76/1990, 26 de abril [RTC 1990, 76], F. 3) ya que, si los unos están obligados a contribuir de acuerdo con su capacidad económica al sostenimiento de los gastos públicos los otros están obligados, en principio, a exigir en condiciones de igualdad esa contribución a todos los contribuyentes cuya situación ponga de manifiesto una capacidad económica susceptible de ser sometida a tributación (STC 96/2002, 25 de abril [RTC 2002, 96], F.J. 7)." 
tratarse de manera igual las situaciones iguales y discriminarse entre las diferentes ${ }^{66}$.

El principio de capacidad económica prescribe que a distintos niveles de titularidad o disponibilidad de la riqueza corresponde una tributación distinta (conforme a la progresividad, encontrándose un límite en la no confiscatoriedad); y que a niveles de riqueza iguales pero cualitativamente diferenciados, corresponde diversa tributación ${ }^{67}$.

Además, el principio de capacidad económica se concreta a través de criterios como el de progresividad tributaria en cuanto modula la presión fiscal conforme al nivel de capacidad económica de los contribuyentes; por esto último, el principio de capacidad económica constituye una manifestación del principio de solidaridad tributaria, ya que si bien todas las personas se encuentran sujetas al deber de contribuir, no a todos les afecta con la misma intensidad, o dicho de otro modo, les afecta diferenciadamente ${ }^{68}$.

La progresividad tributaria, a su vez, es limitado por el principio de no confiscatoriedad, como barrera que evita la extinción de la fuente de la riqueza o de la capacidad económica ${ }^{69}$.

Por otro lado, y sin contradecir los principios constitucionales y el de capacidad económica, el TCE ha resuelto que los tributos adicionalmente pueden responder a fines extrafiscales ${ }^{70}$, i.e., a criterios económicos y sociales orientados al cumplimiento de fines de interés público garantizados en la Constitución (STCE 37/1987; STCE 186/1993; STCE 289/2000; STCE 168/2004) y no sólo a la satisfacción de necesidades públicas y de redistribución ${ }^{71}$. Debe hacerse

\footnotetext{
${ }^{66}$ Queralt; Lozano; Tejerizo; Casado, Curso, cit. nota n. 29, p. 127. Por dichas razones, es el sistema tributario como un conjunto (y no con cada figura tributaria en particular) el que debe responder al principio de capacidad económica, lo que así se traduce en el deber constitucional de contribuir.

${ }^{67}$ Carrera Raya, José Francisco, Manual de Derecho Financiero, Vol. I, Derecho Financiero y Teoría de los Ingresos Públicos, Tecnos, Madrid, 1994.

${ }^{68}$ ESEVERRI, Derecho, cit. nota n. 1, p. 30.

${ }^{69}$ En España se ha reiterado los fuertes lazos entre los principios de justicia tributaria. Por ejemplo, la STCE 46/2000, de 17 de febrero, sostuvo que: "La igualdad ante la Ley resulta, pues, indisociable de los principios de capacidad económica, así como de los de generalidad, justicia y progresividad, que se enuncian en el último precepto constitucional citado (SSTC 27/1981, de 20 de julio, FJ 4; 19/1987, de 17 de febrero, FJ 3; 209/1988, de 10 de noviembre, FJ 6; 45/1989, de 20 de febrero, FJ 4; 54/1993, de 15 de febrero, FJ 1, y 134/1996, de 22 de julio, FJ 5)."

${ }^{70}$ Parte de la doctrina cuestiona tanto la vaguedad de este término como su constitucionalidad, ya que la CE en su artículo 31 nada dice a su respecto, y las finalidades extrarrecaudatorias serían contrarias a la idea de impuesto justo. Gallego Peragón justifica estos fines del tributo en principios contenidos claramente en la CE. Ver: Gallego, Los principios, cit. nota n. 45, p. 121.

${ }^{71}$ Es interesante destacar la postura de Gorospe y Herrera, en cuanto a que en los tributos redistributivos y con fines extrafiscales el principio de capacidad económica no podría actuar como criterio general de cuantificación, sino como límite garantístico del mínimo existencial y de la no confiscatoriedad. Cfr.: Gorospe; Herrera, "La virtualidad" cit. nota n. 55, p. 37.
} 
notar que la Constitución Española consagra una serie de funciones estatales de intervención económica y social, entre otros sitios, en sus artículos 9.2, 39 y siguientes, 128 y siguientes, etc., que son mucho menos expresas y enfáticas que en la Constitución chilena.

El Tribunal Constitucional Español en la sentencia 37/1987, de 26 de marzo, por la que resolvió un recurso de inconstitucionalidad interpuesto contra la creación de un impuesto sobre tierras infrautilizadas, en su fundamento jurídico 13 enfatizó que es constitucionalmente admisible establecer impuestos que, sin desconocer o contradecir el principio de capacidad económica o de pago ${ }^{72}$, respondan principalmente a criterios económicos o sociales orientados al cumplimiento de fines o a la satisfacción de intereses públicos que la Constitución preconiza o garantiza, y basta que la capacidad económica exista, como renta real o potencial en la generalidad de los supuestos contemplados por el legislador al crear el impuesto, para que aquel principio constitucional quede a salvo ${ }^{73}$.

En definitiva, el criterio de tributación con arreglo a la capacidad económica muestra estrecha ligazón con los otros principios constitucionales tributarios y, no obstante su gran importancia, también se encuentran justificadas las excepciones basadas en otros principios o valores constitucionales, los que pueden conducir a finalidades extrafiscales. De ahí que resulta necesario realizar una ponderación de bienes jurídicos entre el principio de capacidad económica y los demás valores o principios en juego ${ }^{74}$.

La doctrina ha destacado que en un grupo relevante de sentencias ${ }^{75}$ el TCE ha reconocido de modo implícito que la Constitución consagra un derecho

\footnotetext{
${ }^{72}$ Albiñana resuelve la cuestión del mismo modo, señalando que el tributo puede considerar finas no fiscales, pero que jamás puede renunciar al principio de capacidad económica sin éste abdicaría de su propio fundamento. No constituyen tributos, para este autor, las exacciones públicas que prescinden totalmente de este principio. Por ejemplo, las exacciones públicas cuyo objeto es proteger el medio ambiente, es un caso de "tributos no tributarios". AlbiÑana, cit. nota 26, p. 12.

${ }^{73}$ STCE 37/1987, de 26 de marzo, FJ 13: "Es cierto que la función extrafiscal del sistema tributario estatal no aparece explícitamente reconocida en la Constitución, pero dicha función puede derivarse directamente de aquellos preceptos constitucionales en los que se establecen principios rectores de política social y económica (señaladamente artículos 40.1 y 130.1), dado que tanto el sistema tributario en su conjunto como cada figura tributaria concreta forman parte de los instrumentos de que dispone el Estado para la consecución de los fines económicos y sociales constitucionalmente ordenados. Por otra parte, dicha función está expresamente enunciada en el artículo 4 de la vigente Ley General Tributaria, según el cual 'los tributos, además de ser medios para recaudar ingresos públicos, han de servir como instrumentos de política económica general, atender a las exigencias de estabilidad y progreso sociales y procurar una mejor distribución de la renta nacional'. A ello no se opone tampoco el principio de capacidad económica establecido en el artículo 31.1 de la Constitución, pues el respeto a dicho principio no impide que el legislador pueda configurar el presupuesto de hecho del tributo teniendo en cuenta consideraciones extrafiscales".

${ }^{74}$ Herrera, "El Principio", cit. nota n. 22.

${ }^{75}$ Entre las que se encuentran las sentencias del TCE 45/1989 (de 20 de febrero, especialmente FJ $7^{\circ} 7$ ), 146/1994 (de 12 de mayo), 214/1994 (de 14 de julio), 194/2000 (de 19 de julio), 96/2002, 255/2004 (de 22 de diciembre).
} 
fundamental a contribuir a los gastos públicos conforme a la capacidad económica ${ }^{76}$, como especificación del derecho a la igualdad. En ellas, el Tribunal realiza una ponderación entre las necesidades de practicabilidad administrativa o la lucha contra el fraude y el principio de capacidad económica, superando el genérico control de interdicción de la arbitrariedad ${ }^{77}$.

En virtud de lo anteriormente mencionado, las desviaciones del principio de capacidad económica sólo serán legítimas si superan el control de proporcionalidad (ponderación ${ }^{78}$, pues es posible restringir un derecho cuando deba tutelarse otro valor constitucionalmente relevante, pero a condición de mantener la integridad del contenido esencial del derecho afectado. Ello será lícito si resulta idóneo para conseguir el objetivo perseguido; si resulta necesario (en cuanto no pueda lograrse el mismo resultado por otro medio menos gravoso para el afectado); y siempre que dicha restricción del derecho fundamental resulte proporcionada al fin (positivo) perseguido ${ }^{79}$. La capacidad económica está constituida por la riqueza disponible, y el legislador únicamente podrá desviarse del reparto de la carga tributaria conforme a ella bajo las restricciones del control de proporcionalidad ${ }^{80}$, y sin quebrantar el núcleo esencial de este derecho, constituido por el mínimo exento y la prohibición de confiscatoriedad ${ }^{\beta 1}$.

\section{7. Ámbito de control normativo del principio de capacidad económica}

Otra cuestión compleja es si el principio de capacidad económica reconoce sus efectos sobre el sistema impositivo en su globalidad o en cada una de las figuras tributarias en particular.

\footnotetext{
${ }^{76}$ Gorospe; Herrera, "La virtualidad" cit. nota n. 55, p. 33.

77 Herrera, "El Principio", cit. nota n. 43; Gorospe; Herrera, "La virtualidad" cit. nota n. 55, p. 43.

${ }^{78}$ Herrera, "El Principio", cit. nota n. 22. Específicamente sobre cómo opera en general el principio o control de proporcionalidad -institución poco conocida y no aplicada en Chile-: Alexy, Robert, "Constitutional Rights, Balancing and Rationality", Ratio luris Vol. 16, № 2, June, 2003, pp. 131-140. En relación a la materia tributaria y el principio de capacidad económica, ver Herrera Molina, Pedro Manuel, Capacidad económica y sistema fiscal, Marcial Pons, Madrid, 1998, pp. 76 y 96. En España se han escrito importantes monografías acerca de esta materia: Fernández Nieto, Josefa, Principio de proporcionalidad y derechos fundamentales: una perspectiva desde el derecho público común europeo, Dykinson S.A. y Servicio de Publicaciones de la Universidad Rey Juan Carlos, Madrid, 2008; Bernal Pulido, Carlos, Principio de proporcionalidad y derechos fundamentales, CEPC, Madrid, 2003.

${ }^{79}$ Herrera, "El Principio", cit. nota n. 43, p. 40.

${ }^{80}$ Por cierto, el control de proporcionalidad o ponderación de derechos y bienes constitucionalmente protegidos no es lo mismo que el "principio de proporcionalidad" que parte de la doctrina constitucional chilena deriva de la prohibición de establecer tributos manifiestamente desproporcionados e injustos, como en gran confusión pretende Fernández González. Cfr., Fernández GonzÁLEz, Miguel Ángel, "Principios constitucionales de proporcionalidad y justicia en materia tributaria", Revista Chilena de Derecho № 2 Vol. 27, 2000, pp. 357-371, passim.

${ }^{81}$ Herrera, "El Principio", cit. nota n. 43, p. 41.
} 
Existe una norma constitucional clara en España, a diferencia de lo que sucede en Chile, mediante la cual se mandata al legislador para establecer un sistema tributario justo basado en diversos principios, entre ellos, el que es objeto principal de este análisis. De esto se podría derivar que el efecto normativo debe recaer en la generalidad del sistema de impuestos. Con todo, lo anterior no sería una razón suficiente o concluyente para negar la influencia de los principios de justicia tributaria en cada uno de los tributos en particular.

Aun cuando existen opiniones en todos los sentidos ${ }^{82}$, es razonable pensar que si las exigencias de justicia fiscal sólo se predicaran sobre el conjunto del sistema y no sobre cada figura que lo integra, se desvanecerían completamente las garantías de los valores fundamentales que están en la base de los límites de la imposición ${ }^{83}$, ya que la función primaria del principio es la de enjuiciar cada ley en particular ${ }^{84}$. Del mismo modo en que cada tributo debe ser analizado a la luz de los principios materiales, debe serlo, en definitiva, todo el sistema.

Sobre esta misma cuestión, se ha planteado, acertadamente, que el ajuste de la norma legal al principio de capacidad económica debe efectuarse tanto en el plano normativo como en el momento de la realización de la norma, debiendo observarse la gestión de cada figura impositiva, por lo que el Tribunal Constitucional debe llevar a cabo tanto un control normativo (evaluar la estructura normativa de modo abstracto) como de los resultados que se siguen de su aplicación (control de los resultados) ${ }^{85}$.

82 Para algunos autores, es el sistema tributario como un conjunto (y no con cada figura tributaria en particular) el que debe responder al principio de capacidad económica, lo que así se traduce en el deber constitucional de contribuir (Queralt; Lozano; Tejerizo; Casado, Curso, cit. nota n. 29, p. 127); Fernández Segado considera que los principios materiales de justicia tributaria se proyectan sobre el conjunto del sistema tributario y no sólo sobre todas y cada una de las diferentes figuras que lo integran. Calvo Ortega parece situarse en el otro extremo, al sostener que el principio de capacidad económica retrata una "situación subjetiva patrimonial en relación con obligaciones dinerarias determinadas", aunque se trataría de un planteamiento "puramente lógico: tiene capacidad económica el titular de una situación patrimonial concreta y suficiente frente a la obligación tributaria que se derive de esa misma situación", por lo que la capacidad económica se predica ante una obligación tributaria concreta. Este principio se extiende a todos los tributos -tasas, contribuciones especiales e impuestos- y a todas las personas, jurídicas o físicas (Calvo, Curso, cit. nota n. 24, p. 52). Para Gallego Peragón el principio de capacidad económica opera, sin ninguna reserva, frente al sistema tributario en su conjunto y no frente a cada figura impositiva particular, pues de otro modo se desvirtuaría el concepto constitucional de justicia tributaria (GAllego, Los principios, cit. nota n. 45, p. 118).

${ }^{83}$ CASADO, "El principio", cit. nota n. 7, p. 219.

${ }^{84}$ PalaO, "Apogeo", cit. nota n. 9, p. 397.

${ }^{85}$ CASADO, "El principio", cit. nota n. 7, p. 197. Agrega que se está "ante unas demandas constitucionales que lo que exigen del legislador no son ampulosas declaraciones de estilo, sino resultados aplicativos concretos y es, por tanto, en virtud de éstos como corresponde controlar el cumplimiento del mandato constitucional" (CASADO, "El principio", cit. nota n. 7, p. 198). La CE consagra principios y derechos materiales y no únicamente formales, por lo que el objeto de control debe ser la ley y, además, el resultado de aplicación de la ley. En su carácter de norma obligatoria, la Constitución exige a la Admi- 
Con todo, se mantiene abierta la tradicional distinción entre imposición directa e indirecta, lo que no implica que deba justificarse en detalle y cuidadosamente cada postura por la gravedad de las consecuencias en los derechos de los contribuyentes. EI TCE parece sostener la idea de que los principios de justicia tributaria se proyectan con plenitud exclusivamente sobre las piezas básicas del sistema tributario y no sobre otros aspectos menos importantes (STCE 182/1997, FJ $7^{\circ}$ ). La renta y el patrimonio constituirían, para el TCE, manifestaciones claras de capacidad económica, puesto que no existe norma constitucional que limite el gravamen de otra manifestación de riqueza distinta de la renta ${ }^{86}$.

También el TCE (sentencia 296/1994) ha afirmado que este principio encuentra su más natural acomodo en los impuestos y, especialmente, en los de carácter directo aunque, por cierto, cabe respecto de los demás tributos.

En lo referido a las tasas y las contribuciones especiales, si bien responden a principios de justicia conmutativa todavía cabe espacio, aunque sea limitado, al principio de capacidad económica, lo que encuentra sustento en el artículo 74 de la Ley Orgánica de Financiación de las Comunidades Autónomas y 24.4 de la Ley Reguladora de Haciendas Locales, y así ha sido declarado en la STCE 296/1994 (de 10 de noviembre) ${ }^{87}$. En definitiva, el impacto de estos principios sobre esta clase de tributos ha sido sintetizado en los siguientes términos, expuestos por Gorospe Oviedo y Herrera Molina ${ }^{88}$ :

a) Principio de financiamiento preferentemente impositivo de los gastos realizados en relación con el conjunto de los ciudadanos.

b) En la medida que el importe de las tasas se separe del coste (costo) del servicio - del principio de equivalencia- la desviación queda plenamente sometida al principio de capacidad económica.

c) El principio de capacidad económica impondrá desviaciones del principio de equivalencia, cuando sea necesario para garantizar el mínimo exento personal y familiar o la prohibición de confiscatoriedad.

\section{La jurisprudencia constitucional y el principio de capacidad económica}

No existen muchos pronunciamientos constitucionales, ya que el TCE ha decidido que no es posible recurrir al recurso de amparo constitucional para

nistración y a los jueces ordinario y constitucional adecuar sus decisiones administrativas o judiciales a ella, mediante diferentes técnicas jurídicas acordes a cada una de esas instancias y conforme a las exigencias derivadas del control normativo y del control de resultados, dejando siempre a salvo el principio consagrado en la norma constitucional,

${ }^{86}$ Gorospe; Herrera, "La virtualidad" cit. nota n. 55, p. 43.

${ }^{87}$ Gorospe; Herrera, "La virtualidad" cit. nota n. 55, p. 49.

${ }^{88}$ Gorospe; Herrera, "La virtualidad" cit. nota n. 55, p. 49. 
tutelar el principio de capacidad económica, como en general ha sucedido frente a todas las disposiciones o derechos contenidos en el artículo 31 constitucional. Con todo, en conexión con la igualdad tributaria se ha admitido el recurso en algunos casos en virtud del artículo $14 \mathrm{CE}$, y ha existido algún pronunciamiento sobre el principio de capacidad económica por cuanto el TCE ha razonado que este principio constituye la medida de la igualdad. Asimismo, se ha referido a este principio otras veces, principalmente con ocasión de recursos o cuestiones de inconstitucionalidad ${ }^{89}$.

En los casos en que se ha pronunciado, el TCE constantemente ha destacado la importancia de la capacidad contributiva, al reiterar que "a efectos de contribuir a los gastos públicos, tanto significa como la incorporación de una exigencia lógica que obliga a buscar la riqueza allí donde la riqueza se encuentra" (STC 27/1981, FJ 4; reiterada en STC 150/1990, FJ 9; STCE 221/1992, FJ 4; STCE 233/1999, FJ 23ㅇ. Asimismo, en sentencia 194/2000 FJ $7^{\circ}$, al Tribunal le ha parecido que "el tributo..., por imperativo del artículo $31.1 \mathrm{CE}$, sólo puede exigirse cuando existe capacidad económica y en la medida -en función- de la capacidad económica (STC 182/1997, de 28 de octubre, FJ 6º'"90.

Se ha interpretado que el TCE ha sustentado una concepción de la capacidad económica como real, individual, efectiva, cierta o existente (SSTCE 27/1981, 209/1988, 45/1989, 221/1994, 214/1994, 194/2000), pero, además, como potencial, puesta de manifiesto en la generalidad de los supuestos contemplados por el legislador al crear un impuesto (SSTC 37/1987, FJ 13; 186/1993, FJ 4; 14/1998, FJ 11º B; 295/2006); y que este principio se vulnera si se pretende gravar rentas inexistente o ficticia (STC 221/1992, FJ 4) o aparentes o no reales (STC 194/2000, FJ $7^{\circ}$ ).

Finalmente, se destaca que, aun cuando el principio de capacidad económica es predicable para la generalidad del sistema tributario, se ha visto relativizado respecto de las tasas (STC 182/1997 y STCE 296/1994; Sentencia del Tribunal Supremo de 30 de noviembre de 2002).

Se ha defendido, en la doctrina, que la jurisprudencia del TCE presenta una notable ambigüedad que hunde sus raíces en una concepción vacilante del principio de igualdad ${ }^{91}$ (como he expuesto en profundidad en otro lugar, el principio de capacidad económica se vincula de modo muy estrecho con la igualdad tributaria ${ }^{92}$ ).

\footnotetext{
${ }^{89}$ Gorospe; Herrera, "La virtualidad" cit. nota n. 55, p. 31.

${ }^{90}$ MedinA, "Las Obligaciones", cit. nota n. 17.

${ }^{91}$ Herrera, "El principio" cit. nota n. 22,

${ }^{92}$ Masbernat, Patricio, "El principio de capacidad económica como principio jurídico material de la tributación (III): Su elaboración doctrinal en España a partir de su relación con los otros principios de justicia tributaria"; y MASBERNAT, Patricio "El principio de capacidad económica (V): El principio de igualdad tributaria como su base dogmática. La perspectiva del Derecho español"; ambos artículos de próxima publicación.
} 
Una corriente jurisprudencial mayoritaria considera al principio de igualdad como un mero mandato de interdicción de la arbitrariedad y, en cuanto tal, permite al legislador otorgar un tratamiento distinto a supuestos semejantes (que manifiesten la misma capacidad económica) siempre que la diferencia se funde en una justificación razonable, quedando este principio reducido a un mero criterio más en el que puede inspirarse el legislador para respetar las exigencias constitucionales de justicia tributaria. ${ }^{93}$

La evaluación que se ha hecho de esta postura es que, si bien presenta la ventaja aparente de conciliar la libertad del legislador democrático con el control constitucional del TCE, en la práctica conduce a la construcción de "planteamientos excesivamente laxos y complacientes con el legislador" ${ }^{\prime \prime 4}$.

La otra línea jurisprudencial considera la capacidad económica como la medida de la igualdad en materia tributaria, que puede modularse en atención a otros principios constitucionales (incluidas la practicabilidad y la lucha contra el fraude como exigencias implícitas en el deber de contribuir), exigiéndose en este caso, por tanto, que la desviación del principio de capacidad económica sea proporcionada al fin que se persigue.

\section{A MODO DE CONCLUSIONES}

A partir del Derecho Español, puedo concluir que, en general, tanto el principio de capacidad económica como el principio de igualdad, son manifestaciones del principio de razonabilidad. De hecho, la primera exigencia de la justicia es la igualdad, y la primera exigencia de la igualdad sobre el tributo es la capacidad económica. Por ello, países cuyas constituciones no hacen referencia expresa a la capacidad económica, como sucede con Chile, bien pueden llegar (y lo han hecho otros) a las mismas conclusiones que en aquellos en que sí aparece expresamente consagrado. Una cuestión esencial, en nuestro medio, entonces, es profundizar en el estudio de la igualdad tributaria ${ }^{95}$.

Se ha dicho, con razón, que sin riqueza no hay tributos. Únicamente la riqueza debe tributar (STCE 37/1987). Es el fundamento de dicho deber, y el

\footnotetext{
${ }^{93}$ El profesor Herrera Molina resume de este modo esta línea jurisprudencial: "En definitiva, el legislador es libre para gravar o no determinada manifestación de riqueza siempre que pueda encontrarse cualquier motivo que lo justifique (el que el parlamento haya considerado oportuno): El tributo sólo lesionará el principio de capacidad económica si no es posible encontrar ninguna explicación para la diferencia de trato. En estos casos la inconstitucionalidad podrá salvarse por dos vías: gravando por igual todos los supuestos o exonerándolos a todos". Herrera, Capacidad, cit. nota n. 58.

${ }^{94}$ Gorospe; Herrera, "La virtualidad", cit. nota n. 55, p. 33.

${ }^{95}$ Sobre las carencias dogmáticas de la igualdad tributaria, se expone en mi estudio "El principio de capacidad económica como principio jurídico material de la tributación (I): Razones de su necesaria adopción, en el ordenamiento jurídico chileno, a partir de un enfoque crítico de su jurisprudencia constitucional", de próxima publicación.
} 
impuesto debe graduarse atendiendo a la capacidad individual de pago, y no sólo porque el obligado es un ser capaz de obtener rendimientos (i.e., porque se le puede sustraer algo) sino porque la comunidad jurídica, representada por el Estado, tiene una parte esencial en el surgimiento y conservación de esa capacidad de enriquecimiento individual ${ }^{96}$.

Pero no toda riqueza es susceptible de contribuir a los gastos públicos para la satisfacción de las necesidades comunes, porque hay un mínimo de riqueza que se requiere para satisfacer las propias necesidades, para la propia subsistencia. Ese límite mínimo de riqueza debe mantenerse libre de impuestos, constituye una zona de inmunidad fiscal. No existe una regla acerca de su cantidad, varía en cada tiempo y lugar. Ese mínimo no se refiere al necesario para la existencia biológica, sino para la subsistencia digna.

También hay un límite máximo, protegido por el principio de no confiscatoriedad (STCE 150/1990), el cual supone la incorporación de una exigencia lógica de no agotar la riqueza con el pretexto del deber de contribuir. Tampoco es un límite preciso, no existe una cifra. La cifra del $50 \%$ sugerida por el Tribunal Constitucional Alemán tampoco es clara, pues no indica, por ejemplo, si corresponde a la renta neta o bruta (íntegra) ${ }^{97}$.

Por otro lado, debe considerarse tanto la presión fiscal directa como la indirecta, los impuestos sobre los bienes, y los costes necesarios para el cumplimiento de las normas tributarias (la obligación tributaria principal o material y las accesorias o formales).

La capacidad económica se expresa bien en el impuesto directo (renta), pues es presupuesto y límite de éste, constituye el criterio de cuantificación de la determinación del impuesto. Aquí, este principio funciona como medida de igualdad.

Respecto del impuesto indirecto ( $v$.g, IVA) el principio de capacidad económica también tiene expresión, aunque de modo diferente que en el impuesto directo (el cual grava la renta). El impuesto indirecto grava la capacidad económica ínsita en el hecho imponible, expresado en el consumo de un bien: a mayor consumo mayor impuesto.

Pero se puede decir algo más sobre el impacto de la capacidad económica respecto de los impuestos indirectos, en particular el impuesto sobre el consumo. Este presupone una evidencia social, cual es que cada uno dispone y utiliza un patrimonio mínimo para financiar sus necesidades existenciales y

\footnotetext{
${ }^{96}$ KIRCHHOF, Paul, "La influencia de la Constitución Alemana en su legislación tributaria", disponible En: Base de datos http://www.tirantonline.com Identificador de documento TOL314.020 [visitado el 27/10/2009].

${ }^{97}$ Herrera Molina, Pedro Manuel, “Una decisión audaz del Tribunal Constitucional alemán: el conjunto de la carga tributaria del contribuyente no puede superar el 50 por 100 de sus ingresos", Impuestos № 14, 1996.
} 
que su tratamiento tributario debe prever, por ejemplo, el no gravamen de los medicamentos y costes de alquiler y servicios básicos, y la discriminación de los tipos impositivos ${ }^{98}$ de los alimentos.

Por su parte, la tasa (categoría de tributo) se paga por la obtención de un servicio de la Administración y según el coste de éste, y no porque se tenga capacidad económica. Pero aun así debe integrarse dicho principio a fin de que se manifieste, aunque sea de modo limitado, para reducir e incluso dispensar de su pago (siempre que la medida resulte practicable). Pero, al contrario, no puede servir para incrementar la tasa en razón de una mayor capacidad económica.

La capacidad económica, como se ha visto, tiene expresión tanto en el ingreso como en el gasto; en la igualdad como en la redistribución; en los derechos humanos individuales, como en los derechos humanos sociales.

El Derecho Financiero debe cumplir el papel de darle contenido al deber del Estado de promover la dignidad humana. La persona tiene derechos fundamentales porque tiene necesidades fundamentales, y a su vez para satisfacer las segundas deben limitarse los primeros. Y aquí entra el Derecho Financiero: el Estado debe mediar para la provisión de los recursos necesarios y suficientes para que los servicios públicos atiendan a las necesidades de las personas, asignándolos de modo eficiente. Asimismo, debe arbitrar las condiciones sociales y económicas (tributarias) que permitan a la sociedad su desarrollo económico y social, a fin de que, también, las personas adopten una conducta de responsabilidad social.

Igualmente en este punto deben considerarse técnicas jurídicas (como la ponderación o el juicio de proporcionalidad) que resuelvan estas tensiones entre los derechos individuales con los derechos sociales, los intereses generales y los públicos, y los bienes reconocidos constitucionalmente.

Ahora, en lo que respecta a su incorporación en el ordenamiento jurídico chileno, ya he mencionado que el principio de capacidad económica ha sido preterido, en su carácter de principio jurídico material de la tributación, por la doctrina, la jurisprudencia y el legislador. Sin embargo, presenta claras posibilidades de ser introducido, a partir de materiales normativos propiamente nacionales.

La entrada de este principio puede tener lugar sobre la base del principio de igualdad tributaria (que no debe considerarse exclusivamente una mera reiteración del principio de igualdad formal ante la ley del artículo $19 \mathrm{~N}^{\circ} 2$, aunque esta norma también debiera ser interpretada con otro prisma), en una relectura sistemática contemplando los artículos $1^{\circ}$ y $5^{\circ}$ de la Constitución chilena, y especialmente en virtud de la interdicción de tributos injustos. Para

${ }^{98}$ En Chile usamos la expresión "tasa del impuesto", que me parece inadecuada por confundirse con una categoría de tributos ("las tasas"). 
ello, se requiere de una interpretación constitucional acorde al estado actual de las exigencias del Derecho, superar la petrificación constitucional derivada de una interpretación originalista, evaluando con justicia y criterio jurídico los documentos histórico-constitucionales. Con todo, a mi entender, el abandono de una interpretación originalista no nos conduce a una interpretación mutativa.

Nótese, además, que tan sólo el debate y análisis del principio de capacidad económica abre la puerta al desarrollo de todos los demás principios materiales de la tributación, por la profunda interrelación (que no confusión) existente entre ellos $^{99}$. Hoy, ad portas de la instalación de una nueva jurisdicción tributaria en Chile, estas cuestiones toman especial relevancia.

Respecto del medido impacto del Derecho Comparado en el ordenamiento jurídico chileno, específicamente en relación a los principios de justicia tributaria, he ido entregando planteamientos particulares en cada uno de los artículos de la serie a que este trabajo pertenece. No obstante las posibles derivaciones que de lo expuesto en este opúsculo puedan surgir respecto de cada materia o cuestión anexa, no cabe duda que cada una de ellas merece un tratamiento separado, lo que, como he indicado, me he esforzado en efectuar.

\section{BibLIOGRAFÍA}

Albiñana García-Quintana, César, "El gasto público", en Alzaga Villamil, Óscar (coord.), Comentarios a la Constitución Española de 1978, Tomo III, Cortes Generales-Editoriales de Derecho Reunidas, Madrid, 1996.

AleXY, Robert, "Constitutional Rights, Balancing and Rationality", Ratio luris No 2 Vol. 16, June, 2003.

Alguacil Marí, María Pilar, "Capacidad económica como parámetro de enjuiciamiento", Revista de Derecho Financiero y Hacienda Pública № 253, 1999.

Aste, Christian, Curso de Derecho y Código Tributario, 2ª edición, Santiago, LexisNexis, 2006.

Bernal Pulido, Carlos, Principio de proporcionalidad y derechos fundamentales, Centro de Estudios Políticos y Constitucionales, Madrid, 2003.

Calvo Ortega, Rafael, Curso de Derecho Financiero, I. Derecho Tributario, Parte General, 10 $0^{a}$ edición, Thomson-Civitas, Madrid, 2006.

Carrera Raya, José Francisco, Manual de Derecho Financiero, Vol. I, Derecho Financiero y Teoría de los Ingresos Públicos, Tecnos, Madrid, 1994.

${ }^{99}$ Masbernat, Patricio, "El principio de capacidad económica como principio jurídico material de la tributación (III): Su elaboración doctrinal en España a partir de su relación con los otros principios de justicia tributaria", de pronta publicación. 
Casado Ollero, Gabriel, "El principio de capacidad y el control constitucional de la imposición indirecta (II). El contenido constitucional de la capacidad económica", Revista Española de Derecho Financiero No 34, 1982.

Collado Yurrita, Miguel Ángel; Moreno González, Saturnina, "Tema 2: Principios constitucionales del Derecho Tributario", en Collado Yurrita, Miguel Ángel (director); Luchena Mozo, Gracia María (coord.), Derecho Tributario, Parte General, 2 ${ }^{a}$ edición, Madrid, Editorial Atelier, 2007.

Eseverri Martínez, Ernesto, Derecho Tributario: Parte General, Tirant lo Blanch, Valencia, 2006.

Falcón y TelLa, Ramón, "Exenciones y capacidad contributiva: la paradoja de la exención de los bienes necesarios para el desarrollo de actividades empresariales", Quincena Fiscal Aranzadi № 7/1995, disponible En: Base de datos http://www.westlaw.es Identificador del documento BIB 1995\1249 [visitado el 27/10/2009].

, "El nuevo IRPF y la capacidad contributiva (II): coeficientes de corrección monetaria y rendimientos irregulares", Quincena Fiscal Aranzadi № 2/1999, disponible En: Base de datos http://www.westlaw.es Identificación del documento BIB 1998\1313 [visitado el 27/10/2009].

, "El nuevo IRPF y la capacidad contributiva (I): mínimo personal y familiar e individualización de rentas", Quincena Fiscal Aranzadi № 1, 1999, disponible En: Base de datos http://www.westlaw.es Identificador del documento BIB 1998\1137 [visitado el 27/10/2009]).

, "El tipo único (flat tax) en el IRPF y la sorprendente propuesta de tipos progresivos en el IBI". Quincena Fiscal Aranzadi, № 20/2004, disponible En: Base de datos http://www.westlaw.es Identificador del documento BIB 2004\1757 [visitado el 27/10/2009]).

Fernández González, Miguel Ángel, "Principios constitucionales de proporcionalidad y justicia en materia tributaria", Revista Chilena de Derecho № 2 Vol. 27, 2000.

Fernández Nieto, Josefa, Principio de proporcionalidad y derechos fundamentales: una perspectiva desde el derecho público común europeo, Dykinson S.A. y Servicio de Publicaciones de la Universidad Rey Juan Carlos, Madrid, 2008.

Fernández Segado, Francisco, "El diseño constitucional del deber de contribuir al sostenimiento de los gastos públicos", Revista Vasca de Administración Pública, Herri-Arduralaritzako Euskal Aldizkaria No 47, 1, 1997, pp. 79-111.

Gallego Peragón, José Manuel, Los principios materiales de justicia tributaria, Comares, Granada, 2003.

Gandra Da Silva Martins, Ives, "Capacidad económica y capacidad contributiva", Revista de Derecho Financiero y de Hacienda Pública, Vol. 41 No 212, 1991. 
Gorospe Oviedo, Juan Ignacio; Herrera Molina, Pedro Manuel, "La virtualidad del principio de capacidad económica en el ordenamiento tributario español", en Albiñana García-Quintana, César; González García, E.;_Ramallo Massanet, Juan; Lejeune Valcárcel, Ernesto; Yábar Sterling, A., Estudios en homenaje al profesor Pérez de Ayala (coords.), Dykinson, Madrid, 2007.

Herrera Molina, Pedro Manuel, "Una decisión audaz del Tribunal Constitucional alemán: el conjunto de la carga tributaria del contribuyente no puede superar el 50 por 100 de sus ingresos", Impuestos N N 14, 1996.

, "El principio de capacidad económica en Alemania y su relevancia para el derecho español", Noticias de la Unión Europea No 150, 1997.

Aspectos internacionales del Impuesto sobre la Renta y capacidad económica", en VV.AA., La Justicia en el Diseño y Aplicación de los Tributos, IEF, Madrid, 2006.

Capacidad económica y sistema fiscal, Marcial Pons, Madrid, 1998, pp. 76-96.

, "El Principio de Capacidad Económica", disponible En: Base de datos de http://www.iustel.es Identificador de documento RI §910978 [visitado el 16/11/2009].

KIRCHHOF, Paul, "La influencia de la Constitución Alemana en su legislación tributaria", disponible En: Base de datos http://www.tirantonline.com Identificador de documento TOL314.020, [visitado el 27/10/2009].

Masbernat, Patricio, "El principio de capacidad económica como principio jurídico material de la tributación (III): Su elaboración doctrinal en España a partir de su relación con los otros principios de justicia tributaria", de pronta publicación.

"El principio de capacidad económica (V): El principio de igualdad tributaria como su base dogmática. La perspectiva del Derecho español"; de próxima publicación.

Medina Guerrero, Manuel, "Las Obligaciones Tributarias", disponible En: Base de datos http://www.iustel.es Identificador de documento RI \$910504 [visitado el 06/11/2009].

Mongay I Soler, M., "Aplicabilidad del principio de capacidad económica como fuente material del Derecho en la jurisprudencia", Revista Española de Derecho Financiero No 87, 1995.

Nogueira Alcalá, Humberto, "La igualdad ante los tributos en el derecho constitucional chileno", Revista de Derecho y Jurisprudencia, 2008, disponible En: Base de datos http://www.microjuris.cl Identificador del Documento: MJD277 [visitado el 12/11/2009].

Palao Taboada, Carlos, "Apogeo y crisis del principio de capacidad contributiva", Estudios jurídicos en homenaje al profesor Federico de Castro Vol. II, 1976. 
Palao Taboada, Carlos, "Nueva visita al principio de capacidad contributiva", Revista Española de Derecho Financiero № 124, 2005.

Queralt, Martín; Lozano, Carmelo; Tejerizo, José; Casado, Gabriel, Curso de Derecho Financiero y Tributario, $18^{a}$ edición, Tecnos, Madrid, 2007.

Radovic Schoepen, Ángela, Obligación tributaria, Editorial Jurídica ConoSur, Santiago de Chile, 1998.

Rodríguez Bereijo, Álvaro, "Jurisprudencia constitucional y principios de la imposición", disponible En: Base de datos http://www.tirantonline.com Identificación del documento TOL314.024, [visitado el 03/11/2009].

Romero García, Felipe, El valor sistema tributario: acerca de su integración entre los principios de la imposición, Servicio de Publicaciones de la Universidad de Cádiz, Cádiz, 2005.

Sainz de Bujanda, Fernando, Lecciones de Derecho Financiero, $5^{\text {a }}$ edición, Universidad Complutense de Madrid, Facultad de Derecho, Madrid, 1991. 
